\title{
ESTABELECIMENTO DE UM PROTOCOLO DE SOROAGLUTINAÇÃO RÁPIDA (SAR) PARA DETECÇÃO DE ANTICORPOS PARA Salmonella Typhimurium EM SUÍNOS
}

\author{
Rosecler Alves Pereira, ${ }^{1}$ Marisa Macagnan, ${ }^{2}$ Patricia Schwarz, ${ }^{3}$ \\ Claudio Wageck Canal ${ }^{4}$ e Verônica Schmidt ${ }^{5}$
}

\begin{abstract}
1. Médica veterinária, doutora em Ciências Veterinárias pelo Programa de Pós-Graduação em Ciências Veterinárias, UFRGS
2. Médica veterinária, doutora pelo Programa de Pós-Graduação em Ciências Veterinárias

3. Médica veterinária, doutoranda pelo Programa de Pós-Graduação em Ciências Veterinárias

4. Departamento de Patologia Clínica Veterinária. Áreas de atuação: virologia e sanidade animal

5. Departamento de Medicina Veterinária Preventiva. Áreas de atuação: produção e sanidade animal; saneamento aplicado. E-mail: verônica.schmidt@ufrgs.br
\end{abstract}

\section{RESUMO}

A Salmonella Typhimurium é um dos principais agentes isolados de casos de toxinfecção alimentar humana no Brasil. Os produtos de origem animal são as principais fontes de infecção e a carne suína e seus derivados são muito relevantes na sua manutenção e transmissão para o homem. A monitorização das salmoneloses na suinocultura é realizada com testes bacteriológicos e sorológicos, como ELISA. No entanto, trata-se de testes que demandam tempo e possuem um custo elevado. A soroaglutinação rápida (SAR) é um teste rápido, pouco dispendioso e que pode ser realizado a campo. Com o intuito de padronizar um teste de SAR para soro suíno, foram testadas sessenta amostras de soro suíno, sendo trinta sororreagentes e trinta não reagentes ao ELISA padrão. Com o soro não diluído, determinou-se que a SAR exibiu sensibilidade, especificidade, valor preditivo positivo e valor preditivo negativo iguais a 96,7\%, demonstrando que a soroaglutinação rápida, usando como antígeno Salmonella Typhimurium, é um teste de triagem eficaz para a detecção de anticorpos contra esse patógeno em soro de suínos, apresentando alta sensibilidade, especificidade e valor preditivo positivo.

PALAVRAS-CHAVES: Anticorpo, diagnóstico, Salmonella Typhimurium, soroaglutinação rápida, suíno.

\section{ABSTRACT}

\section{RAPID AGGLUTINATION TEST (RAT) FOR THE DETECTION OF ANTI-Salmonella Typhimurium ANTIBODY IN SWINE}

Salmonella Typhimurium is an important agent isolated from cases of human food poisoning in Brazil. Animal-origin products are the main source of infection, and pork has been implicated in Salmonella transmission to humans. Programs to salmonella monitoring in swine have been carried out, using bacteriological and serological tests like ELISA. However, these tests are time-consuming and expensive. The rapid agglutination test (RAT) is cheaper, faster and easier. Aiming to standardize RAT to detect anti-salmonella antibodies in swine serum, 60 samples of swine serum were tested. They had previously displayed positive (30) or negative (30) results in the ELISA test. The results showed that RAT had sensitivity, specificity, predictive positive value and predictive negative value equal to $96.7 \%$ when non-diluted serum was tested. Thus, this test can be applied to detect antibodies against $S$. Typhimurium in swine serum.

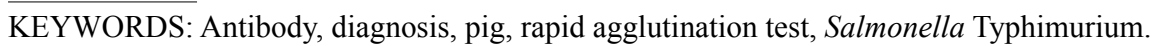




\section{INTRODUÇÃO}

Nas ultimas décadas, Salmonella sp. tem sido um dos principais agentes relacionados a surtos de toxinfecção intestinal em humanos (NADVORNY et. al. 2000). Os alimentos de origem animal têm sido apontados como os veículos mais importantes para a salmonelose humana de origem alimentar (JACKSON et al., 1991). Segundo MORES \& ZANELLA (2006), a salmonelose é a segunda etiologia mais importante nas infecções alimentares em humanos, e Salmonella Typhimurium tem sido um dos principais sorotipos isolados (HOFER \& REIS, 1994; WALL et al., 1994; DAVIES et al., 1996; SÃO PAULO, 2005).

Na última década, houve um aumento no número de casos de salmonelose humana em decorrência do consumo de carne suína contaminada (BERENDS et al., 1998; MAGNANI et al., 2000). Sugere-se que isso ocorreu em virtude do aumento na prevalência de Salmonella na produção, no abate e no processamento da carne desses animais (BORCH et al., 1996; SWANENBURG et al., 2001; BESSA et al., 2004).

Em um trabalho para determinar a prevalência de Salmonella isolada ao abate de suínos no Rio Grande do Sul, BESSA et al. (2004) determinaram que os sorovares mais prevalentes foram Typhimurium (24,3\%), seguido por Agona (19,9\%), Derby (13,2\%) e Bredeney (12\%). Este trabalho confirmou dados de outros países (KAMPELMACHER et al., 1963; DI GUARDO et al., 1992; KÄSBOHRER et al., 1997; GANTER et al., 1998) e do Brasil (PELUFFO et al., 1946; ZEBRAL et al., 1974), em que Salmonella Typhimurium foi a mais isolada de suínos sadios.

Dado o aumento do consumo e da produção da carne suína, deveria haver um maior controle sanitário em todas as etapas de produção, visando à diminuição do risco para a saúde pública. Por exemplo, SWANENBURG et al. (2001) propuseram que o abate de animais provenientes de rebanhos livres separadamente de rebanhos sororreagentes ou infectados por Salmonella poderia ser útil na redução do número de carcaças de suínos contaminadas após o abate. Para isso, vários métodos vêm sendo utilizados para o monitoramento de rebanhos, como isolamento do agente e técnicas sorológicas, como ELISA.

Teoricamente, qualquer técnica sorológica pode ser utilizada como teste de triagem. Entretanto, a es- colha se faz em função de diferentes propriedades das técnicas, em favor daquelas que são simples, práticas, rápidas e econômicas (TOMA et al., 1999). A maioria das técnicas não pode ser realizada a campo, decorrendo em maior tempo para a emissão de resultados, prejudicando a agilidade do processo de monitoria e consequentemente na tomada de decisões.

$\mathrm{Na}$ avicultura industrial, a soroaglutinação rápida é um teste de triagem utilizado no monitoramento de várias doenças, inclusive salmoneloses. Segundo WRAY \& DAVIES (1994), a soroaglutinaçao rápida é uma prova simples, prática e pouco dispendiosa. No entanto, sua prática não é comum na suinocultura e não há antígenos comerciais disponíveis para $S$. Typhimurium no mercado. Nesse sentido, o objetivo do presente estudo foi a padronização de uma técnica de soroaglutinação rápida (SAR) para determinar a presença de anticorpos para Salmonella Typhimurium e outras salmonelas paratíficas em soro suíno.

\section{MATERIAL E MÉTODOS}

Utilizaram-se sessenta amostras de soros sanguíneos de suínos previamente testados pela técnica de ELISA (KICH et al., 2003) para a presença de anticorpos para Salmonella sp. Dessas, trinta amostras eram provenientes de animais sororreagentes (positivos) para salmonela e trinta de animais não reagentes. O ponto de corte proposto para o teste de ELISA é a densidade óptica (DO) de 0,169 (KICH et al., 2004) e no presente estudo não foram incluídas amostras com reação suspeita no teste de ELISA.

A técnica de soroaglutinação rápida (SAR) foi adaptada da descrita por CANAL et al. (2005). Como antígeno utilizou-se uma cepa de Salmonella Typhimurium isolada de fígado de ema (Rhea americana) no Rio Grande do Sul e sorotipada pela Fiocruz-RJ. A cepa foi cultivada em TSA (Tryptic Soy Agar) por 24 horas e após este período, com o auxílio de um suabe estéril, as colônias foram coletadas e suspendidas em 2-3 mL de solução salina tamponada com fosfato (PBS). A suspensão foi homogeneizada e padronizada para a densidade do tubo 2 da escala de MacFarland. Após, o soro a ser testado foi diluído em PBS na proporção de 1:10. Misturaram-se $25 \mu \mathrm{L}$ de suspensão bacteriana e $25 \mu \mathrm{L}$ de soro não diluído ou $25 \mu \mathrm{L}$ de soro diluído sobre uma placa de vidro, homogeneizando a mistura 
por cerca de um minuto. Decorrido esse período, realizou-se a leitura indicando a amostra como positiva ou negativa pela presença ou ausência de aglutinação, respectivamente.

A determinação da sensibilidade, especificidade, valores preditivos positivo e negativo, índice kappa e a construção da curva ROC (Receiver Operator Characteristics) foi realizada utilizando-se o software SPSS for Windows, versão 12.0.2 (SPSS Inc., Chicago, 2004), tomando o teste ELISA como padrão. Categorizou-se o índice kappa como sem concordância $(\mathrm{k}<0,00)$ a quase perfeito $(0,81<\mathrm{k}<1,0)$ (ABRAIRA, 2000).

\section{RESULTADOS E DISCUSSÃO}

As sessenta amostras foram, inicialmente, testadas pela técnica de SAR utilizando-se o soro não diluído. Observou-se concordância quase perfeita entre os resultados obtidos por essa técnica e os resultados do teste de ELISA $(\mathrm{k}=0,933)$, sendo que apenas duas amostras não apresentaram concordância de resultado entre os dois testes (Tabela 1).

TABELA 1. Tabela de contingência para comparação dos resultados da soroaglutinação rápida (SAR) com ELISA em soros não diluídos de suínos, utilizando Salmonella Typhimurium como antígeno

\begin{tabular}{lccc}
\hline \multicolumn{1}{c}{ SAR } & \multicolumn{3}{c}{ ELISA } \\
\hline & Positivo & Negativo & Total \\
Positivo & 29 & 1 & 30 \\
Negativo & 1 & 29 & 30 \\
Total & 30 & 30 & 60 \\
\hline
\end{tabular}

Tomando-se o teste ELISA como padrão, determinou-se que a SAR, nessas condições, possui sensibilidade, especificidade, valor preditivo positivo e valor preditivo negativo iguais a 96,7\%. Esses resultados indicam um pequeno número tanto de resultados falsos positivos quanto negativos.

Entretanto, utilizando-se a SAR com os soros na diluição de 1:10, obteve-se concordância mediana $(\mathrm{k}=0,633)$ nos resultados entre os dois testes, observando-se apenas vinte amostras reagentes com a SAR (Tabela 2). Neste caso, essa técnica apresentou menor sensibilidade (66,7\%), valor preditivo positivo $(95,2 \%)$ e valor preditivo negativo $(74,4 \%)$, mantendo a mesma especificidade $(96,7 \%)$.

TABELA 2. Tabela de contingência para comparação dos resultados do ELISA com os da soroaglutinação rápida (SAR) em soros sanguíneos diluídos (1:10) de suínos, utilizando Salmonella Typhimurium com antígeno

\begin{tabular}{lccc}
\hline \multicolumn{1}{c}{ SAR } & \multicolumn{3}{c}{ ELISA } \\
\hline & Positivo & Negativo & Total \\
Positivo & 20 & 10 & 30 \\
Negativo & 10 & 20 & 30 \\
Total & 30 & 30 & 60 \\
\hline
\end{tabular}

Observou-se que a SAR, quando realizada com soro diluído, gerou um maior número de resultados falsos negativos, não sendo, portanto, indicada como um teste de triagem adequado nos casos de infecção por Salmonella sp. Isto porque um bom teste de triagem é aquele que fornece um máximo de resultados corretos e um mínimo de resultados falsos, ou seja, possui alta sensibilidade e especificidade. Nos testes de triagem com a finalidade de identificar animais infectados, seria preferível identificarem-se erroneamente animais sadios como doentes (falsos positivos) a manterem-se as fontes de infecção (falsos negativos) no rebanho, indicando a sensibilidade como propriedade desejável em técnicas diagnósticas de triagem (TOMA et al., 1999).

MAINAR-JAIME \& BARBERA'N (2007) observaram concordância alta $(\kappa=0,93)$ entre os resultados da soroaglutinação e ELISA no diagnóstico de infecção por Toxoplasma gondii em ovinos, sendo determinada sensibilidade de $92,6 \%$ e $95,5 \%$, respectivamente.

Tanto em aves (TAN et al., 1997; JOUY et al., 2005) quanto em suínos (KICH, 2003) o teste de ELISA apresentou alta sensibilidade, sendo este um método adequado para identificação de infecção por Salmonella em rebanhos suínos (NIELSEN et al., 1995) e aves (JOUY et al., 2005).

A sensibilidade e a especificidade são atributos intrínsecos do teste. No entanto, para estimar a validade de um instrumento diagnóstico em condições operacionais deve ser calculado um indicador denominado 
valor preditivo positivo (probabilidade de um caso identificado com um determinado instrumento de ser de fato positivo), cujo valor varia com a prevalência (WALDMAN \& ROSA, 2009). No presente estudo, a SAR, tanto com soro bruto quanto diluído, apresentou o mesmo valor preditivo positivo $(95,2 \%)$.

A acurácia global ou validade da SAR no diagnóstico presuntivo de infecção por Salmonella foi de 97,2\% (Figura 1). A área sob a curva ROC mede a probabilidade de concordância entre duas medidas (FLETCHER et al., 1996), em que uma área de $50 \%$ reflete ausência de força (poder discriminatório) na relação e uma área de $100 \%$ reflete concordância perfeita (SCHROEDER et al., 2001).

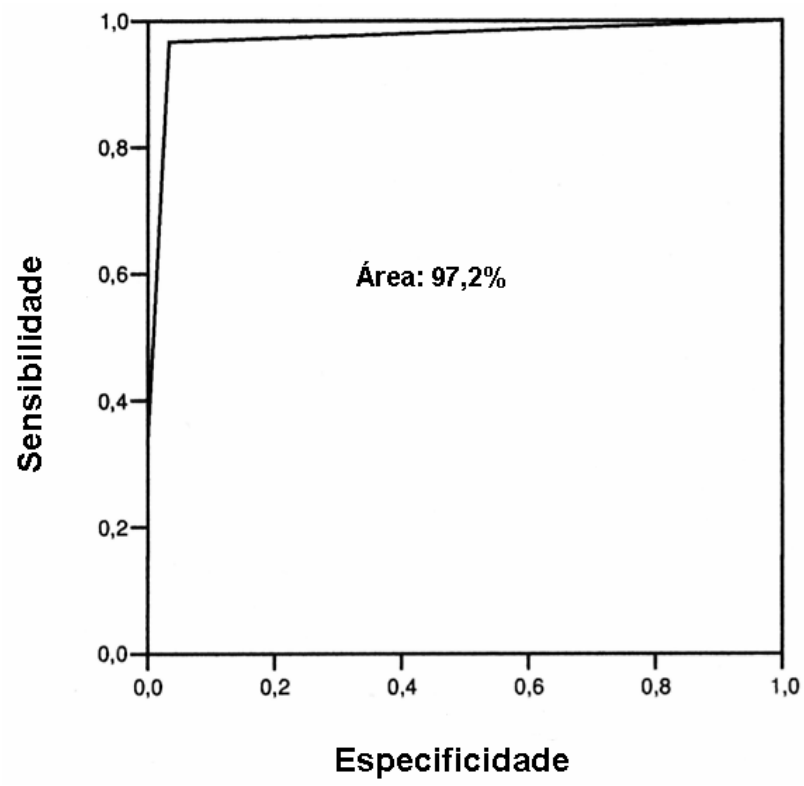

FIGURA 1. Curva Roc da técnica de soroaglutinação rápida para identificação de resposta imune de soros suínos, utilizando Salmonella Typhimurium como antígeno.

O teste de ELISA é uma ferramenta que pode e deve ser usada para determinar a infecção por Salmonella em rebanhos suínos, visando seu controle (KICH et al., 2006). Entretanto, com base nos resultados apresentados, verifica-se que o teste de SAR em soro de suínos para determinar animais sororreagentes com a $S$. Typhimurium é válido e, utilizando-se soro suíno bruto (não-diluído), é possível sua realização.

\section{CONCLUSÕES}

O protocolo descrito de soroaglutinação rápida que usa antígeno de Salmonella Typhimurium foi um teste de triagem eficaz para detectar anticorpos em soro de suínos, apresentando alta sensibilidade, especificidade e valor preditivo positivo.

\section{REFERÊNCIAS}

ABRAIRA V. El índice kappa. Semergen, v. 27, p. 247-249, 2000.

BERENDS, B. R.; KNAPEN, F.; MOSSEL, D. A. A.; BURT, S. A.; SNIJDERS, J. M. Impact on human health of Salmonella spp. on pork in the Netherlands and the anticipated effects of some currently proposed control strategies. International Journal of Food Microbiology, v. 44, n. 3, p. 219-229, 1998.

BESSA, M. C.; COSTA M.; CARDOSO M. Prevalência de Salmonella sp em suínos abatidos em frigoríficos do Rio Grande do Sul. Pesquisa Veterinária Brasileira, v. 24, n. 2, p. 80-84, 2004.

BORCH, E.; NESBAKKEN, T.; CHRISTENSEN, H. Hazard identification in swine slaughter with respect to foodborne bacteria. International Journal of Food Microbiology, v. 30, n. 1/2, p. 9-25, 1996.

CANAL, C. W.; LEÃO, J. A.; ROCHA S. L. S.; MACAGNAN, M.; LIMA-ROSA, C. A. V.; OLIVEIRA, S. D.; BACK, A. Isolation and characterization of Ornithobacterium rhinotracheale from chickens in Brazil. Research in Veterinary Science, v. 78, p. 225-230, 2005.

DAVIES, A.; O'NEILL, P.; TOWERS L.; COOKE, M. An outbreak of Salmonella typhimurium DT104 food poisoning associated with eating beef. Communicable Diseases Report. CDR Review, v. 6, n. 11, p. 159-162, 1996.

DI GUARDO, G.; FONTANELLI, G.; PANFILI, G.; CONDOLEO, R.; DE GROSSI, L.; BROZZI, A. M.; BOZZANO, A. I. Occurrence of Salmonella in swine in the Latium Region (Central Italy) from 1980 to 1989: a retrospective study. Veterinary Quarterly, v. 14, n. 2, p. 62-65, 1992.

FLETCHER, R. H.; FLETCHER, S. W.; WAGNER E. H. Epidemiologia clínica: elementos essenciais. 3. ed. Porto Alegre: Artes Médicas, 1996. 281 p.

GANTER, M.; MULLER, K.; TEGELER, R.; FRIEDEL, K. Prevalence of Salmonella in finishing pigs of Northwest Germany. In: IPVS CONGRESS, 15., 1998. Birmingham, England. Proceedings... Birmingham, England, 1998. p. 70.

HOFER, E.; REIS, E. M. F. Salmonella serovars in food poisoning episodes recorded in Brazil from 1992 to 1991. Revista do Instituto de Medicina Tropical, v. 36, n. 1, p. 7-9, 1994. 
JACKSON, G. J.; LANGFORD, C. F.; ARCHER, D. L. Control of salmonellosis and similar foodborne infections. Food Control, v. 2, p. 26-34, 1991.

JOUY, E.; PROUX, K.; HUMBERTA, F.; ROSE, V.; LALANDE, F.; HOUDAYER, C.; PICAULT, J. P.; SALVAT, G. Evaluation of a french ELISA for the detection of Salmonella Enteritidis and Salmonella Typhimurium in flocks of laying and breeding hens. Preventive Veterinary Medicine, v. 71, p. 91-103, 2005.

KAMPELMACHER, E. H.; GUINÉE, P. A.; HOFSTRA K.; VAN KEULEN, A. FURTHER studies on Salmonella in slaughterhouses and in normal slaughter pigs. Zentralblat Veterinary Medizin B, v. 10, n. 2, p. $27,1963$.

KÄSBOHRER, A. M.; GEUE, L.; STAAK, C. H.; STEINBACH, G.; RABSCH, W.; HELMUTH, R.; BLAHA, T. H.; PROTZ, D. Prevalence of Salmonellae in German slaughter pigs as detected by cultural, serological and PCR techniques. In: SALMONELLAAND SALMONELLOSIS, 1997. Ploufragan, France. Proceedings... Ploufragan, France, 1997. p. 315-320.

KICH, J. D.; CARDOSO, M.; COLDEBELLA, A.; PIFFER, I. A.; VIZZOTTO, R.; SILVA, L. E.; CATAGNA, S. Teste de ELISA para monitoramento da infecção por Salmonella em suínos. In: CONGRESSO DE VETERINÁRIOS ESPECIALISTAS EM SUÍNOS, 11., 2003, Goiânia. Anais... Goiânia, 2003.

KICH, J. D.; SCHWARZ, P.; CARDOSO, M.; TRIQUES, N. J.; VIZZOTTO, R.; RAMENZONI, M. L. F. O uso da sorologia (ELISA) para monitorar a infecção por Salmonella em rebanhos suínos. Concórdia: Comunicado Técnico 442, 2006.

MAINAR-JAIME, R. C.; BARBERA'N, M. Evaluation of the diagnostic accuracy of the modified agglutination test (MAT) and an indirect ELISA for the detection of serum antibodies against Toxoplasma gondii in sheep through Bayesian approaches. Veterinary Parasitology, v. 148, p. 122-129, 2007.

MULLER, M.; SCHWARZ, P.; MICHEL, T.; KICH, J. D.; CARDOSO, M. R. I. Avaliação do status sorológico e de isolamento de Salmonella em suínos no início da terminação e ao abate. In: CONGRESSO LATINO-AMERICANO DE SUINOCULTURA, 2., 2004, Foz do Iguaçu. Anais... Foz do Iguaçu, 2004. p. 490-491.

MAGNANI, A. L.; GIOMBELLI, A.; SHUCK, M. S.; BUSATO, M. A.; SILVA, N. L. Incidência de Salmonella e Escherichia coli em carne suína in natura e salame colonial consumidos pela população de Chapecó, SC. Higiene Alimentar, n. 14, p. 44-47, 2000.

MORES, N.; ZANELLA, J. C. Perfil sanitário da suinocultura no Brasil. Disponível em: $<$ http://www.nordesterural.com.br/dev/nordesterural/matler.asp?newsId=3402> . Acesso em: $1 .^{\circ}$ set. 2006.
NADVORNY, A.; FIGUEIREDO, D. M. S.; SCHMIDT, V. Ocorrência de Salmonella sp. em surtos de doenças transmitidas por alimentos no Rio Grande do Sul, em 2000. Acta Scientiae Veterinariae, v. 32, p. 47-51, 2004.

NIELSEN, B.; BAGGESEN, B.; BAGER, F.; HAUGEGAARD, J.; LIND, P. The serological response to Salmonella serovars typhimurium and infantis in experimentally infected pigs. The time course followed with an indirect anti-LPS ELISA and bacteriological examinations. Veterinary Microbiology, v. 47, n. 3-4, p. 205-218, 1995.

PELUFFO, C. A.; BIER, O.; AMARAL, J. P. J. Estudos sobre as salmoneloses em São Paulo. Memórias do Instituto Butantan, n. 19, p. $211-228,1946$.

SÃO PAULO. Toxinfecção alimentar por Salmonella em um evento científico, São Paulo, 2004, Secretaria de Estado da Saúde de São Paulo, Divisão de Doenças de Transmissão Hídrica e Alimentar do CVE/CCD-SES, Revista de Saúde Pública, v. 39, n. 3, 2005.

SCHROEDER, K.; WEGSCHEIDER, K.; ZEYMER, U. Extent of ST-segment deviation in a single electrocardiogram lead 90 min after thrombolysis as a predictor of medium-term mortality in acute myocardial infarction. The Lancet, n. 358, p. 14791486, 2001.

SWANENBURG, M.; URLINGS, H. A.; SNIJDERS, J. M.; KEUZENKAMP, D. A.; VAN KNAPEN, F. Salmonella in slaughter pigs: prevalence, serotypes and critical control points during slaughter in two slaughterhouses. International Journal of Food Microbiology, v. 70, n. 3, p. 243-254, 2001.

TAN, S.; GYLES, C. L.; WILKIE, B. N. Comparison of an LPSspecific competitive ELISA with a motility enrichment method (MSRV) for detection of Salmonella Typhimurium and S. Enteritidis in chickens. Veterinary Microbiology, v. 56, p. 79-86, 1997.

TOMA, B.; DUFOUR, B.; SANAA, M.; BENET, J. J.; SHAW, A.; MOUTOU, F.; LOUZÃ, A. Epidemiologia aplicada. MaisonAlfort: FAO, 1999. 676 p.

WALDMAN, E. A.; ROSA, T. E. C. Validade de instrumento diagnóstico (Anexo 2). In: Vigilância em saúde pública. Disponível em: <http://portalses.saude.sc.gov.br/arquivos/sala_de_leitura/ saude_e_cidadania/ed_07/09.html $>$. Acesso em: 11 naio 2010.

WALL, P. G.; MORGAN, D.; LAMDEN, K.; RYAN, M.; GRIFFIN, M.; THRELFALL, E. J.; WARD, L. R.; ROWE, B. A case control study of infection with an epidemic strain of multiresistant Salmonella typhimurium DT104 in England and Wales. Communicable Diseases Report. CDR Review, v. 4, n. 11, p. 130-135, 1994. 
WRAY, C.; DAVIES, R. H. Guidelines on detection and monitoring of salmonella infected poultry flocks with particular reference to Salmonella enteritidis. In: REPORT OF A WHO CONSULTATION ON STRATEGIES FOR DETECTION AND MONITORING OF SALMONELLA INFECTED POULTRY FLOCKS, Austria: WHO - Veterinary Public Health Unit, 1994. p. 29-34.
ZEBRAL, A. A.; FREITAS, C. A.; HOFER, E. Ocorrência de Salmonella em gânglios linfáticos de suínos aparentemente normais, abatidos no matadouro de Santa Cruz, cidade do Rio de Janeiro, Guanabara. Memórias do Instituto Oswaldo Cruz, v. 72, n. 3, p. 223-235, 1974.

Protocolado em: 27 abr. 2009. Aceito em: 18 maio 2010. 